\section{SPINAL ANASTHESIA, WITH SPECIAL REFERENCE TO THE ACUTE ABDOMEN.}

BY PERCIVAL P. COLE, M.B., Ch.B. BIRM., F.R.O.8. ENG.,

SURGEON, KING GHORGE HOSPITAL, AND WEST HAN AND EASTERN GENERAL HOSPITAL; OPERATING SURGEON, BROOK WAR HOSPITAT; ASSISTANT SURGEON, SEAMEN'S HOSPTTAL, GREENWICH, AND THE CANCER HOSPITAL, BROMPTON, S.W.

MY experience of this form of anæsthesia extends over a period of five years. For three years and a half I used the heavy, or Barker's, dextrose solution of stovaine, strength 5 per cent. During that time I limited its use to operations below the umbilicus, and rarely employed it for any abdominal operation other than appendicectomy and operations on the bladder. Eighteen months ago, acting on the advice of Mr. G. Ramsey Phillips, I abandoned the heavy solution, and have since used exclusively the Billon solution of stovaine in sodium chloride, strength 10 per cent. The advantages of the light over the heary solution are as follows : (1) rapidity and constancy of action ; (2) tilting posture unnecessary, thus allowing administration on any table, improvised or otherwise ; (3) the head is kept lower than the feet throughout the operation; (4) the Trendelenburg position can be adopted as soon as the operator may wish; and (5) the higher average level of analgesia.

The operations performed with this form of anæsthesia incluảe plating for fractured tibia and femur; fractured patella; removal of semilunar cartilage; varicose veins; skin grafting; amputations of lower extremity; hernia, femoral, inguinal, umbilical and ventral, strangulated and otherwise ; varicocele ; hæmorrhoids ; removal of testicle ; radical cure of hydrocele; internal urethrotomy; external urethrotomy ; cystoscopy ; cystotomy ; prostatectomy ; appendicectomy ; hysterectomy ; salpingectomy ; cholecystostomy; perforated gastric ulcer; gastrostomy; and gastro-enterostomy. The ages of the patients have ranged from 6 months to 70 years.

The value of spinal anæsthesia in operations known to be attended by shock to the patient is generally recognised theoretically, and in this class of case its use is distinctly indicated. An interesting example was that afforded by a patient whose thigh I amputated through the hip-joint. This patient, a male aged 54 , had a myxochondroma of the femur. $\mathrm{He}$ had long-standing aortic disease, and seemed a poor surgical risk. His pulse-rate never rose above 90 , and the next morning he was reading the newspaper.

In operations on the urethra stovaine is, from the surgeon's point of view, ideal. Relaxation is so absolute that the difficulties are reduced to a minimum, and such a thing as impassable stricture ceases to exist. In a case of extensive extravasation of urine $I$ was able, after making the usual free incisions, to perform an internal urethrotomy with excellent result.

In prostatectomy the method has been sufficiently emphasised by Mr. H. M. Page ${ }^{1}$ who has also recently contributed an article on its use in abdominal surgery. ${ }^{2}$ Its rôle in this latter sphere demands further consideration. Here the psychic factor assumes added importance. It is the psychic factor which is, I believe, responsible for the prejudice which has limited and cramped the use of spinal anæsthesia. It is a fundamental principle, if success is to be attained, that psychic influences shall be reduced to vanishing point. Mr. Page accomplishes this by administering a small quantity of general anæsthetic. The same result can usually be obtained, less easily, I admit, by strict attention to technique.

It is essential to recognise that spinal stovaine is an anæsthetic and consequently should be administered by a competent anæsthetist, with all the ritual of a planned and considered performance. It is precipitating failure to usher forthwith a nervous patient into an operating theatre with its unaccustomed atmosphere and evidences of fearsome preparation. Before the puncture is made the mind is a prey to nervous fears and forebodings. Then perhaps follows an investigation as to the level of analgesia. Small wonder is it that the patient so treated will feel things without being touched.

The technique recently adopted with complete success is as follows. A preliminary injection of morphia and atropine is given half an hour to one hour before the time fixed for operation. The spinal puncture is made in the anæsthetising room, the patient being told that she will not actually lose consciousness, but will be drowsy and will feel nothing. The eyes are bandaged, the ears plugged with cotton-wool, and suggestions are made that the patient goes to sleep. She is then wheeled into the operating theatre and lifted on to the table, and so arranged that the feet are higher than the head, this position being maintained throughout the operation. The towels are arranged and the field of operation is made ready. No testing to determine the level of analgesia is carried out, but the operator watches the face as he clips the towels to the skin. Absolute silence is maintained, not a word being spoken till the operation is completed. Instruments are handled with the utmost care, so that the clank of metal and the click of the artery forceps shall not be audible.

Operating under such conditions is good for everyone concerned; good for the patient, for it induces mental rest; good for the operator, for he must be gentle; good for the assistant, for he must be alert and intelligent; good for the theatre staff, for they must work accurately and smoothly.

Spinal anæsthesia has its indications in two distinct types of abdominal operations-operations of expediency and operations of urgency. Cases which have come under my care during the last few weeks will serve to illustrate such indications in the expedient class. In these cases the choice of anæsthetic was not a matter of indifference. General anæsthesia was definitely contra-indicated, and would in all probability have determined failure.

A very stout, middle-aged woman was admitted with a ventral hernia. I had removed her uterus 18 months before under a general anæsthetic. For a week afterwards she had vomited violently. Her abdominal muscles were poorly developed and the long-continued strain on the healing wound was, in my opinion, responsible for the development of her hernia. The patient was reluctant to undergo another operation, owing to her dread of this postanæsthetic vomiting, and I was doubtful of success should it again occur. Stovaine was administered in the manner described, dose 7/10 c.c. Progress was quite uneventful, with no vomiting and no headache. When asked which anæsthetic she preferred, the patient emphatically decided in favour of stovaine.

A woman, aged 35 , was admitted with pyloric stenosis. Two previous attempts at operative treatment had been made with a general anæsthetic. On the first occasion it was necessary to perform tracheotomy as soon as the abdomen was opened. On the second occasion urgent symptoms compelled the operator to desist before the abdomen was opened. Stovaine was administered and a posterior gastro-enterostomy performed without any difficulty. The influence of "team work" as a time-saving factor was also clearly demonstrated. The operation from spinal puncture to the last skin stitch was completed in 35 minutes. Three rows of sutures were used for the anastomosis. The abdominal wall was sewn up in four layers. 'The absolute flaccidity of the abdominal parietes is a revelation to those accustomed to operate on the upper abdomen under general anæsthesia only.

It is, however, in the surgery of the acute abdomen that spinal anæsthesia proves of still greater service. It is administered, too, in more favourable circumstances. These patients are in pain, and only too frequently have been so for many hours, perhaps for several days. The immediate relief afforded by spinal anæsthesia produces a mental attitude of tranquillity and confidence, and thus the psychic factor is effectually abolished. From the surgeon's standpoint the conditions for easy and expeditious operating are ideal. Relaxation is more complete than can be obtained with the most profound general anæsthesia; bowel, however greatly distended, shows no tendency to escape from the abdomen, and when displaced obediently maintains its position. A phenomenon which I have frequently noted deserves particular mention. In many cases of obstruction consequent to widespread peritonitis the bowels have acted on the table This forcibly suggests that so-called paralytic ileus of inflammatory origin is not a true paralysis, but is due to an active inhibition, and that these inhibitory impulses are abolished by spinal anæsthesia. In one such case, following closely on an operation for acute 
appendicitis, the patient was taken to the theatre for further operation. Stovaine was administered, but before the abdomen could be opened the patient vomited a large quantity of foul-smelling fluid, and the bowels acted copiously. Operation was deferred, but the obstruction recurred, for which jejunostomy was performed. It was later shown that this recurrent obstruction was mechanical, the terminal portion of the ileum being firmly bound to the pelvic floor by firm inflammatory adhesions. The significance of this observation anent the action of spinal anæesthesia on obstruction, due to spreading peritonitis, is sufficiently obvious. It implies that spinal anæsthesia should invariably be used in acute abdominal lesions associated with such conditions. It would seem, therefore, that this form of anæsthesia should be particularly useful in military abdominal surgery, and I strongly urge its claims in this connexion.

That patients whose condition is so bad as almost to preclude operation can be safely dealt with by this method is shown by the following cases.

A woman, aged 35, was seen in the casualty department of the West Ham Hospital. She had been ill for five days. The abdomen was greatly distended, rigid, and acutely tender. The patient's face was deathly pale ; pulse-rate 160, scarcely perceptible. She was immediately taken to the operating theatre. Stovaine was administered and subcutaneous saline was run into both axillæ. The face almost immediately lost its anxious, drawn look, and the patent dozed throughout the operation. A subumbilical median incision exposed inflamed coils of intestine stuck together by recent lymph. On gently separating the coils pools of pus were evacuated, this condition obtaining from the under-surface of the liver to the bottom of the pelvis. The cause of the peritonitis was a pyosalpinx. Both kidney pouches and the pelvis were drained by large rubber tubes. The operation lasted half an hour. The patient's pulse at the end was better than at the beginning. The bowels acted on the table. Slow but com plete recovery was made.

Another patient was admitted for obstruction due to a very large and old-standing ventral hernia. She was 67 years of age and had been ill for four days, the vomit having become fæcal. Stovaine was administered, subcutaneous saline started, and the operation commenced. The coils of gut were densely adherent to each other and to the sac wall. One coil, about 2 feet long, was found acutely strangulated, but as it showed signs of recovery it was replaced in the abdomen. The patient was perfectly quiet and placid throughout the operation, which lasted just over an hour. She developed a parotitis and an abscess at the site of injection of the saline, but otherwise made an uneventful recovery. The bowels acted copiously on the table.

The advantages of spinal anesthesia to the operator are obvious and incontestable, and my experience leads me to urge that, particularly in the acute abdomen, the advantages to the patient are equally great.

Queen Anne-street, $W$.

\section{OClinical a diltes:}

\section{MEDICAL, SURGICAL, OBSTETRICAL, AND THERAPEUTICAL.}

\author{
NOTE ON A CASE OF BERI-BERI.
}

\author{
By G. Marshall Findlay, M.B., Ch.B. Edin., \\ TEMPORARY SURGKON, R.N.
}

THE following case of beri-beri presents certain interesting features in regard both to the history and the clinical symptoms of the attack.

$\$$ The patient, aged 23, is a leading telegraphist in the Navy and is of somewhat better education than the average nava rating. He entered the service in 1908 at the age of 16 and remained in home waters until February, 1911, when he was ordered to the Persian Gulf. Except for short intervals in Colombo and Bombay, he had spent the whole of the past five years in this part of the world. For the first seven months after arriving in the Gulf he remained in perfect health, but in September, 1911, he noticed that he was becoming weak and easily fatigued, and that his feet and legs were beginning to swell. He did not at this time com plain of any cardiac symptoms, and apparently was entirely cured by three weeks' treatment in the sick bay. During the ensuing winter he contracted malaria while serving ashore but was otherwise healthy. It was not until June, 1912, that signs of oedema again appeared in the feet and legs, accompanied by shortness of breath, palpitation, and loss of deep reflexes-the classical signs of beri-beri. The patient spent four weeks in hospital and then returned to duty.

Throughout 1913 there was no recurrence of any of the symptoms, the patient attributing this to his having been in Colombo during the greater part of the year. It is an interesting fact that beri-beri was formerly very common in Ceylon; so much so that the word beri-beri is derived from an old Singhalese expression meaning weakness; now, however, it is rarely seen in the island. In September, 1914 while cruising in the Indian Ocean, symptoms of beri-ber again occurred, but completely disappeared after eight weeks' treatment in hospital. 'With the exception of a slight attack of malaria in the spring of 1915, the patient remained perfectly healthy until September of last year, when symptoms of the disease again appeared. As before the earliest signs were swelling of the feet and legs and loss of appetite. Later, cardiac symptoms began to develop, characterised by shortness of breath, pain and palpitation over the cardiac region.

In appearance the patient seemed well nourished, though very anæmic. There was marked swelling on the dorsum of the feet, round the ankles, and over the anterior aspect of the legs as high as the junction of the middle and upper thirds. A very slight swelling was also present for a short time over the forearms and hands. The affected areas were symmetrical on the two sides, while the odema was of somewhat firmer consistence than that in Bright's disease. There was never any cedema on the chest or face.

Nervous system.-For the first few days of the illness the deep reflexes were exaggerated, but later they wholly disappeared and remained in complete abeyance for a period of three months. Then the knee-jerks reappeared, to be followed about one month later by the return of the Achilles jerks. At the present time-eight months after the onset of the illness-the knee-jerks are normal, while the Achilles jerks are still somewhat sluggish. Ankle clonus has never been present, and the superficial reflexes have always remained normal. There has been considerable impairment of cutaneous sensation on the dorsum of the fingers and toes, more particularly in regard to touch and pain. A peculiar numb feeling at the tips of the fingers was also complained of for a short time, but this has now completely disappeared.

There was considerable pain on grasping the calf muscles, and a similar symptom was present to a less extent in the muscles of the forearm. The muscular power was good, and at no time was there any evidence of wasting or of the reaction of degeneration. In the gait there was no true ataxia, although the patient habitually walked with his legs straddled and with a slight dragging of the feet. Foot-drop was absent. The "squatting test" described by Willcox" has been well marked and is still present. Rombergism is a striking symptom. The Argyll Robertson pupil, however, is absent, and there are no signs of any parasyphilitic lesion. The Wassermann reaction is negative. A certain amount of incoördination is still present, more particularly in the upper limbs; thus, with the eyes closed the patient is unable accurately to locate the tip of his nose. On the other hand, there is an entire absence of any intention tremor. There has never been any interference with the innervation of the oesophagus or larynx, a not uncommon symptom in beriberi; the special senses also have all remained normal. The mental faculties are unimpaired.

Cardio-vascular system.-The symptoms referable to this system did not develop until about a week after the onset of the odema. They consisted of shortness of breath, palpitation, and slight pain over the cardiac region. On examination the heart was found to be slightly dilated, more particularly towards the right side. The heart sounds were normal, though of a somewhat tic-tac character, while the spacing of the sounds gave rise to the peculiar pendulum like rhythm described by Manson. The pulse was of low tension and easily compressible; it varied in rate from 80 to 100 per minute.

The alimentary system was normal except for the loss of appetite, while the urine never contained any abnormal constituent.

An interesting fact in regard to the above case is that during the two commissions which the patient served in the same ship there were no other instances of beri-beri among the crew. There is no apparent reason why he alone should have fallen victim to the disease. $\mathrm{He}$ is a teetotaller and a moderate smoker, and his diet consisted of the ordinary ship's ration. made up as follows : $1 \mathrm{lb}$. white bread or $\frac{1}{2} \mathrm{lb}$. biscuit; $\frac{1}{2} \mathrm{lb}$. fresh meat; $4 \mathrm{oz}$. preserved meat (twice a week); 1 lb. vegetables, usually potatoes and onions; $4 \mathrm{oz}$. sugar; $\frac{3}{4} \mathrm{oz}$. condensed milk; $1 \mathrm{oz}$. jam; and $\frac{1}{2}$ oz. tea. White rice, butter, and fish were all eaten occasionally, and lime-juice was issued every day. There is only one fact which points to a deficient diet as 